\title{
Study of traits and recalcitrance reduction of field-grown COMT down-regulated switchgrass
}

\author{
Mi Li ${ }^{1,2,3}$, Yunqiao Pu ${ }^{1,2,3}$, Chang Geun Yoo 1,2,3, Erica Gjersing ${ }^{4}$, Stephen R. Decker ${ }^{4}$, Crissa Doeppke ${ }^{4}$, \\ Todd Shollenberger ${ }^{4}$, Timothy J. Tschaplinski 1,2,3, Nancy L. Engle ${ }^{1,2,3}$, Robert W. Sykes ${ }^{5}$, Mark F. Davis ${ }^{5}$, \\ Holly L. Baxter ${ }^{1,6}$, Mitra Mazarei ${ }^{1,6}$, Chunxiang Fu' ${ }^{7}$, Richard A. Dixon ${ }^{1,8}$, Zeng-Yu Wang ${ }^{1,7}$, C. Neal Stewart Jr. ,6 \\ and Arthur J. Ragauskas ${ }^{1,2,3,9^{*}}$
}

\begin{abstract}
Background: The native recalcitrance of plants hinders the biomass conversion process using current biorefinery techniques. Down-regulation of the caffeic acid O-methyltransferase (COMT) gene in the lignin biosynthesis pathway of switchgrass reduced the thermochemical and biochemical conversion recalcitrance of biomass. Due to potential environmental influences on lignin biosynthesis and deposition, studying the consequences of physicochemical changes in field-grown plants without pretreatment is essential to evaluate the performance of lignin-altered plants. We determined the chemical composition, cellulose crystallinity and the degree of its polymerization, molecular weight of hemicellulose, and cellulose accessibility of cell walls in order to better understand the fundamental features of why biomass is recalcitrant to conversion without pretreatment. The most important is to investigate whether traits and features are stable in the dynamics of field environmental effects over multiple years.

Results: Field-grown COMT down-regulated plants maintained both reduced cell wall recalcitrance and lignin content compared with the non-transgenic controls for at least 3 seasons. The transgenic switchgrass yielded 35-84\% higher total sugar release (enzymatic digestibility or saccharification) from a 72-h enzymatic hydrolysis without pretreatment and also had a 25-32\% increase in enzymatic sugar release after hydrothermal pretreatment. The COMT-silenced switchgrass lines had consistently lower lignin content, e.g., 12 and 14\% reduction for year 2 and year 3 growing season, respectively, than the control plants. By contrast, the transgenic lines had 7-8\% more xylan and galactan contents than the wild-type controls. Gel permeation chromatographic results revealed that the weightaverage molecular weights of hemicellulose were 7-11\% lower in the transgenic than in the control lines. In addition, we found that silencing of COMT in switchgrass led to $20-22 \%$ increased cellulose accessibility as measured by the Simons' stain protocol. No significant changes were observed on the arabinan and glucan contents, cellulose crystallinity, and cellulose degree of polymerization between the transgenic and control plants. With the 2-year comparative analysis, both the control and transgenic lines had significant increases in lignin and glucan contents and hemicellulose molecular weight across the growing seasons.
\end{abstract}

Conclusions: The down-regulation of COMT in switchgrass resulting in a reduced lignin content and biomass recalcitrance is stable in a field-grown trial for at least three seasons. Among the determined affecting factors, the reduced biomass recalcitrance of the COMT-silenced switchgrass, grown in the field conditions for two and three seasons, was

\footnotetext{
*Correspondence: aragausk@utk.edu

${ }^{9}$ Department of Chemical and Biomolecular Engineering \& Department

of Forestry, Wildlife and Fisheries, University of Tennessee, Knoxville, TN,

USA

Full list of author information is available at the end of the article
} 
likely related to the decreased lignin content and increased biomass accessibility, whereas the cellulose crystallinity and degree of its polymerization and hemicellulose molecular weights did not contribute to the reduction of recalcitrance significantly. This finding suggests that lignin down-regulation in lignocellulosic feedstock confers improved saccharification that translates from greenhouse to field trial and that lignin content and biomass accessibility are two significant factors for developing a reduced recalcitrance feedstock by genetic modification.

Keywords: Switchgrass, Caffeic acid O-methyltransferase, Biomass recalcitrance, Enzymatic hydrolysis, Lignin, Cellulose accessibility

\section{Background}

In light of the need to reduce net carbon emissions from transportation fuels and to increase energy security, cellulosic ethanol is a promising near-term alternative to fossil fuels due to its domestic abundance, renewability, and favorable net carbon emissions [1, 2]. Switchgrass (Panicum virgatum L.) is a dedicated lignocellulosic biofuel feedstock in the USA, due to its high productivity, flexible adaptability to existing agricultural operations, and low agronomic input requirements [3, 4]. Like other lignocellulosic materials, however, switchgrass cell wall is a complex composite consisting primarily of three biopolymers: cellulose, hemicelluloses, and lignin. The evolved heterogeneity and complexity of plant cell wall structure and components impart natural resistance to enzymatic and microbial deconstruction on lignocellulosic bioresources, which is termed as recalcitrance $[5,6]$. Low biomass recalcitrance favors the economics of the biorefinery.

The recalcitrance of lignocellulosic biomass has been attributed to several factors, such as accessible surface area, lignin content and structure, cellulose crystallinity and degree of polymerization (DP), and hemicellulose content, as well as the presence of acetyl groups [7]. In particular, lignin, a phenolic polymer primarily composed of $p$-hydroxyphenyl $(\mathrm{H})$, guaiacyl $(\mathrm{G})$, and syringyl (S) units, has been regarded as one of the major contributors to recalcitrance by restricting accessibility of enzymes to cell wall polysaccharides and non-productively binding to cellulases $[8,9]$. To overcome the recalcitrance derived from cross-linked lignin and polysaccharide networks, a pretreatment is generally required to break down the lignin-carbohydrate matrix and increase the enzymatic digestibility of cell wall polysaccharides [10]. The drawbacks of the pretreatment process are typically their capital expense, energy costs, and the generation of inhibitors to the subsequent microbial fermentation process in the current bioethanol production platform [10,11].

An alternative promising approach to reduce biomass recalcitrance is to develop genetically engineered feedstock that are more susceptible to pretreatment and eventually to chemical, enzymatic, and microbial digestion $[6,12,13]$. Reduction of recalcitrance has been achieved by altering lignin content and composition through manipulating genes encoding enzymes involved in the lignification process [13]. Caffeic acid/5hydroxyconiferyl aldehyde $O$-methyltransferase (COMT) functions in the synthesis of $\mathrm{S}$ monolignol units by catalyzing the $O$-methylation of the 5-hydroxyl groups of the monolignol precursors 5-hydroxyconiferyl aldehyde and 5-hydroxyconiferyl alcohol [14, 15]. The suppression of COMT activity in switchgrass by RNAi-mediated gene silencing results in a decrease in total lignin content and $\mathrm{S}$ units in biomass, a normal growth phenotype, and improved forage quality [12]. Compared with nontransgenic switchgrass controls, the greenhouse-grown transgenic switchgrass exhibited increased saccharification yield by $17-22 \%$ with pretreatment and $29-38 \%$ without pretreatment, and increased ethanol production yield by $14-28 \%$ in simultaneous saccharification and fermentation (SSF) or by $18 \%$ in consolidated bioprocessing (CBP). In contrast, fermentation inhibition of hot water pretreated COMT-deficient switchgrass without water washing was observed compared with wild-type controls, due to the potential accumulation of monolignollike metabolites [16]. Transgenic switchgrass grown under greenhouse conditions had decreased S/G and $p$-coumarate/ferulate ratios [17]. However, the cellulose crystallinity index (CrI) and DP of transgenic switchgrass were identical to those of controls [12]. A recent study [18] of a 2-year field trial showed that the reduced lignin content of the COMT down-regulated switchgrass was maintained when plants were grown in the field, associated with increased saccharification yield and ethanol yield by up to 34 and $28 \%$, respectively. However, the potential influences of factors such as biomass accessibility or the presence of hemicellulose on the reduced recalcitrance of COMT down-regulated switchgrass have not been examined.

For a better understanding of the structural properties of COMT down-regulated plants grown under field conditions, several factors, including lignin content, cell wall accessibility, cellulose crystallinity, cellulose DP, and molecular weight of hemicellulose, were determined and correlated empirically with enzymatic digestion efficacy. The COMT transgenic switchgrass and their controls 
(non-transgenic switchgrass) from the previous greenhouse study [12] were field-grown and harvested in year 1 to year $3[18,19]$. The field analysis had shown that the COMT2 transgenic line grown in the field exhibited a significant feedstock improvement by yielding over $50 \%$ more liters of ethanol per hectare [18]. The authors also suggested that the plants had reached a more steady-state growth pattern in the second year after the first year of establishment. Therefore, the COMT2 transgenic line and its control harvested in 2012 (year 2) and 2013 (year 3 ) were used in the present study. The main objectives of this study were to (1) assess the sugar release efficiency and characterize the structural differences of field-grown transgenic switchgrass and control, and (2) determine the stability of a few cell wall recalcitrance-related traits and their importance to the enhanced saccharification efficacy in COMT down-regulated switchgrass without pretreatment.

\section{Results}

\section{Chemical composition of switchgrass}

Both the transgenic and control plants were primarily composed of glucan, xylan, and lignin, as well as minor components such as arabinan and galactan (Fig. 1a). Mannan was not detectable in these plants. The distribution of the three significantly changed traits: lignin, xylan, and galactan contents after the 2-year growing period, were compared and are shown in Fig. 1b-d separately. The COMT down-regulated year 2 and year 3 field-grown switchgrass had $12 \%(P<0.0001)$ and $14 \%(P<0.0001)$ less lignin, respectively, compared with the controls (Fig. 1b). This reduction in lignin content is consistent with previous results observed for both the greenhousegrown $(11-13 \%)$ [12, 17] and the field-grown (11-14\%) $[18,19]$ COMT down-regulated switchgrass. In addition, the down-regulation of $C O M T$ resulted in slightly higher polysaccharide content including a $7-8 \%$ increase in xylan $(P<0.01)$ and an $8 \%$ increase in galactan $(P=0.03)$ compared with the controls (Fig. 1c, d). The xylan and galactan contents in transgenic switchgrass of both years 2 and 3 were significantly higher than those in the corresponding controls, whereas this difference was not observed in the field-grown year 1 switchgrass [18]. This variation agreed with the greenhouse-grown switchgrass with a $5-6 \%$ higher xylan content in $\mathrm{T}_{1}$ generation COMT down-regulated lines relative to their controls $[12,17]$.

After the first-year establishment in the field, chemical compositions of the field-grown switchgrass, lignin and glucan contents, varied across the plants' 2-year rotation cycles. Along with the increased biomass yields in Table 1 [19], the lignin contents of the control and transgenic lines increased, by 9 and 6\% $(P<0.0001)$, respectively, in year 3 compared with those in year 2 (Fig. 1b). In addition, we found that year 3 plants also showed a $4-5 \%$ increase $(P<0.05)$ in glucan content with respect to year 2 . The contents of the other measured polysaccharides, arabinan, galactan, and xylan, did not change significantly over the 2-year study period (Additional file 1: Table S1, S6).

\section{Enzymatic digestibility of hydrothermally pretreated and unpretreated switchgrass}

The hydrothermally pretreated (also called autohydrolysis or hot water pretreatment) transgenic samples grown in the field exhibited higher saccharification yield than controls (Fig. 2a) $[18,19]$. We found that the unpretreated transgenic line in both years 2 and 3 exhibited significant increases in saccharification yield with 38 and $84 \%$ higher total sugars released $(P<0.0001)$, respectively, compared with the controls (Fig. 2b). The sugar release improvement in year 2 plants (38\%) was comparable to the greenhouse-grown switchgrass (29-38\%) [12], whereas that in year 3 switchgrass was improved by $84 \%$. On the basis of sugars present in biomass, field-grown switchgrass had a total sugar release of $4-7 \%$, whereas the greenhousegrown switchgrass (green tissues) demonstrated higher sugar releases of about $20-30 \%$ [12].

The enzymatic digestibility of lignocellulosic biomass has been thought to be strongly correlated with lignin content $[8,20]$. By correlating the total sugar release with the lignin content in switchgrass, we found that sugar release of hydrothermally pretreated plants decreased with the lignin content with $R^{2}=0.57$ (Pearson's $r=-0.77, P$ value $=8 \times 10^{-7}$ ) (Fig. 2c). Similarly, an inverse linear relationship with $R^{2}=0.47$ (Pearson's $r=-0.69, P$ value $=3 \times 10^{-5}$ ) of sugar release of unpretreated switchgrass to lignin content was also observed (Fig. 2d).

\section{Cellulose accessibility estimation by Simons' stain}

Simons' stain measures the competitive adsorption between the direct orange (DO) dye 15 and the direct blue (DB) dye 1 on a cellulosic substrate and has been used as a semi-quantitative and relatively easy method to assess the "overall" accessible surface area [21, 22]. To assess the accessibility of unpretreated switchgrass, the adsorption capacities of DO and DB on both transgenic and control plants were measured and compared (Table 1). Avicel PH-101, with 25 and $9 \mathrm{mg} / \mathrm{g}$ maximum adsorption of $\mathrm{DO}$ and $\mathrm{DB}$, respectively, was a positive control and gave values consistent with previous results [23]. The transgenic switchgrass in both years 2 and 3 had a significantly higher $(20-22 \%, P<0.05)$ adsorption capacity of orange $A_{O}$ than its control. However, there was no significant difference observed with respect to $A_{O}$ across 

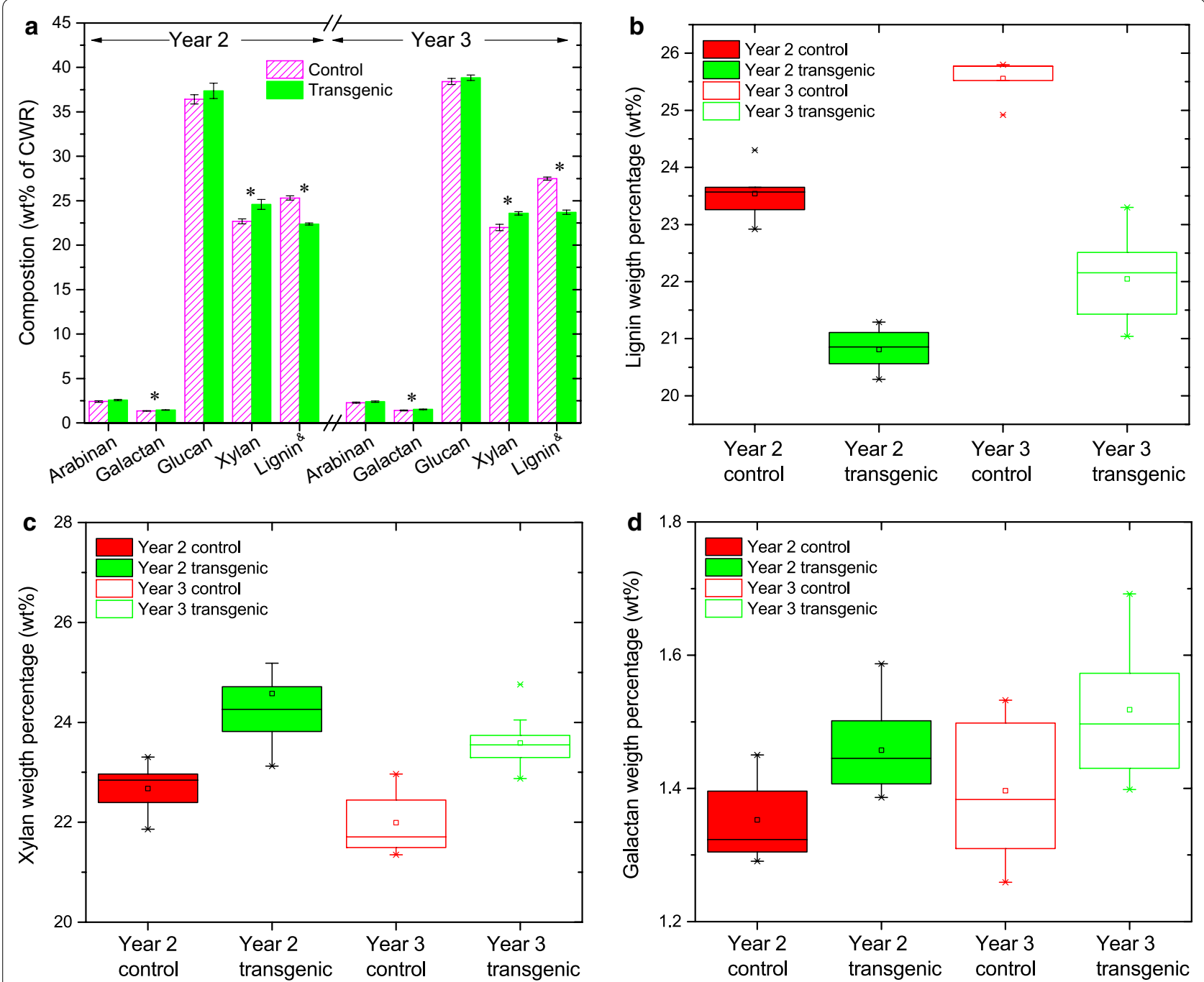

Fig. 1 Chemical composition of field-grown switchgrass in years 2 and 3. The values ( $w t \%$ of cell wall residue) reported are the average of 5 biological replicates from each control group and 10 biological replicates from each transgenic group (a). Error bars represent standard errors. Mannan was not detectable. An asterisk $\left(^{*}\right)$ indicates a significant difference between the transgenic and control groups as determined by a Student's $t$ test $(P<0.05)$. The distributions of lignin $(\mathbf{b})$, xylan $(\mathbf{c})$, and galactan $(\mathbf{d})$ contents in switchgrass were compared. " The lignin content data of year 2 and year 3 plants are from previous publications $[18,19]$

the investigated growing seasons (Fig. 3a). The measured $\mathrm{A}_{\mathrm{O}}$ adsorption was significantly smaller on unpretreated biomass than the pretreated biomass reported in [22] likely due to the cell wall matrix in pretreated biomass being disrupted by pretreatment leading to increased cellulose exposure. Significantly lower DO adsorption was also reported on unpretreated poplar [24, 25]. In addition, the switchgrass adsorbed more orange than blue and the $\mathrm{O} / \mathrm{B}$ ratio was higher in the transgenic (1.35 and 1.09) relative to the control (1.02 and 0.98) group. A positive relationship $\left(R^{2}=0.30\right.$, Pearson's $\left.r=0.57, P<0.001\right)$ was observed between the sugar release and DO adsorption on unpretreated biomass (Fig. 3b).

\section{Molecular weight of cellulose and hemicellulose and crystallinity of cellulose}

The number-average degree of polymerization $\left(\mathrm{DP}_{\mathrm{n}}\right)$ and the weight-average degree of polymerization $\left(\mathrm{DP}_{\mathrm{w}}\right)$ of cellulose from switchgrass were in the range of 400-450 and 3700-3900, respectively (Table 1 ). Comparable with the values (500-700 and 3300-4200 for $\mathrm{DP}_{\mathrm{n}}$ and $\mathrm{DP}_{\mathrm{w}}$, respectively) determined for greenhouse-grown switchgrass [12], the cellulose DP of field-grown transgenic plants did not show significant variation from that of their controls nor changes across growing seasons based on a Student's $t$ test (Additional file 1: Table S5, S6). The extracted hemicellulose from the switchgrass had a $M_{\mathrm{n}}$ of 2.0-2.4 $\times 10^{4}$ 
Table 1 Biomass yields, dyes adsorption on switchgrass, DP of cellulose, and molecular weight of hemicellulose

\begin{tabular}{|c|c|c|c|c|c|c|c|c|c|}
\hline & \multirow{2}{*}{$\begin{array}{l}\text { Biomass yield } \\
Y_{\mathrm{DW}}\left(\mathrm{kg} / \mathrm{m}^{2}\right)\end{array}$} & \multicolumn{3}{|c|}{$\begin{array}{l}\text { Cellulose accessibility } \\
\text { (mg/g) }\end{array}$} & \multicolumn{3}{|l|}{ Cellulose } & \multicolumn{2}{|c|}{$\begin{array}{l}\text { Hemicellulose }\left(\times 10^{3} \mathrm{~g} /\right. \\
\mathrm{mol})\end{array}$} \\
\hline & & $A_{\mathrm{o}}$ & $A_{\mathrm{B}}$ & O/B & $\mathrm{DP}_{\mathrm{n}}$ & $\mathrm{DP}_{\mathrm{w}}$ & PDI & $M_{\mathrm{w}}$ & $M_{\mathrm{n}}$ \\
\hline Reference & & $24.6^{\mathrm{a}}$ & $9.3^{\mathrm{a}}$ & $2.65^{\mathrm{a}}$ & $39 \pm 4^{\mathrm{a}}$ & $283 \pm 12^{a}$ & $7.3^{\mathrm{a}}$ & $18.7 \pm 0.7^{b}$ & $10.8 \pm 0.6^{b}$ \\
\hline Year 2 control & $2.2 \pm 0.2$ & 5.4 & 5.4 & 1.02 & $431 \pm 25$ & $3729 \pm 183$ & 8.7 & $31.6 \pm 3.0$ & $21.6 \pm 3.7$ \\
\hline Year 2 transgenic & $2.6 \pm 0.1^{*}$ & $6.6^{*}$ & 5.0 & 1.35 & $438 \pm 50$ & $3855 \pm 299$ & 8.9 & $29.3 \pm 1.9^{*}$ & $19.7 \pm 2.2$ \\
\hline Year 3 control & $2.5 \pm 0.1$ & 5.3 & 5.5 & 0.98 & $421 \pm 52$ & $3848 \pm 131$ & 9.2 & $36.0 \pm 1.2$ & $23.7 \pm 0.9$ \\
\hline Year 3 transgenic & $2.9 \pm 0.1$ & $6.4^{*}$ & 6.2 & 1.09 & $402 \pm 44$ & $3875 \pm 187$ & 9.7 & $32.1 \pm 3.0^{*}$ & $21.1 \pm 1.6^{*}$ \\
\hline
\end{tabular}

$Y_{\mathrm{DW}}$ is the dry weight biomass yield adapted from literature [19]. The maximum adsorption capacity of orange $\left(A_{\mathrm{O}}\right)$ and blue $\left(A_{\mathrm{B}}\right)$, adsorption ratio of orange to blue (O/B), degree of polymerization (DP) and polydispersity index (PDI) of cellulose, and the average molecular weights of hemicellulose of COMT down-regulated switchgrass and controls. The value reported was the average of 5 biological replicates from each control group and 10 biological replicates from each transgenic group. $\mathrm{DP}_{\mathrm{n}}$ and $\mathrm{DP}_{\mathrm{w}}$ : number-average and weight-average degree of polymerization; $M_{\mathrm{n}}$ and $M_{\mathrm{w}}$ : number-average and weight-average molecular weights; a: Avicel $\mathrm{PH} 101 ;$ b: beech wood xylan. An asterisk $(*)$ for the bold numbers indicates a significant difference between the transgenic and control groups as determined by a Student's $t$ test $(P<0.05)$. \pm is followed by standard deviation

$\mathrm{g} / \mathrm{mol}$ and a $M_{\mathrm{w}}$ of $2.9-3.6 \times 10^{4} \mathrm{~g} / \mathrm{mol}$, and the transgenic plants had $7 \%(P<0.05)$ and $11 \%(P<0.01)$ reduction in $\mathrm{M}_{\mathrm{w}}$ compared with their controls in years 2 and 3, respectively (Table 1; Fig. 4a). The sugar release showed an inverse dependence on the molecular weights of hemicellulose (Additional file 1: Figure S3). The average crystallinity index $(\mathrm{CrI})$ of cellulose isolated from switchgrass from years 2 and 3 were similar, in the range of 36-38\% (Fig. 4b); this similarity between transgenic and control switchgrass was also observed for the greenhouse-grown plants [12].

\section{Discussion}

\section{COMT down-regulation sustained reduced lignin} and indirect impact on polysaccharide contents

The chemical composition of biomass is an important factor for biomass utilization as well as its digestibility [7]. As greenhouse-grown COMT down-regulated switchgrass has exhibited a significant reduction of lignin content and biomass recalcitrance, the variation of their chemical composition and performance occurs when plants are subjected to field trials with extended environmental stresses $[18,26]$. The lignification (and biomass recalcitrance) may be influenced by abiotic (e.g., temperature changes, light and oxidative stress, water deficiency, etc.) and biotic (e.g., pathogen infection) stresses [27]. Our results showed that the field-grown switchgrass had a similar chemical composition as the same cultivated line grown in a greenhouse. Compared with the control plants, the reduced lignin content of COMT down-regulated switchgrass was maintained in the field for the first three seasons. Interestingly, lignin content in both the transgenic and control switchgrass lines showed a significant increase across the three harvest years when grown in the field (e.g., 18.1 and $20.4 \%$ in year 1, 20.8 and $23.5 \%$ in year 2 , and 22.1 and $25.6 \%$ in year 3 , respectively) $[18,19]$. The lignin content increase in field-grown switchgrass from year 1 to year 2 is expected given the longer time available for lignification in the second growing season. The further increase between years 2 and 3 is also expected given the relationship between biomass (plant size revealed by biomass yields in Table 1) and lignification as the plants grow older. In addition, both the year 2 and year 3 field-grown transgenic lines had different polysaccharide contents from the control plants. This difference was mainly caused by $7-8 \%$ higher xylan and $7-8 \%$ higher galactan contents, whereas the largest polysaccharide proportion in biomass, glucan content, was comparable between the transgenic and control plants. The xylan content increase, $14 \%$ in control and $22 \%$ in COMT lines, was also observed in year 2 in comparison to year 1 [18]. Therefore, COMT downregulation in switchgrass also had an indirect increase of hemicellulose in the plant cell wall.

\section{Improved sugar release preserved in the field-grown transgenic switchgrass}

The hydrothermal pretreatment is one of the promising technologies to reduce biomass recalcitrance by breaking down plant cell wall intricacy and making polysaccharides more accessible and amenable to enzymes [28]. The amount of sugars released from the plant cell wall is then used to estimate the biomass recalcitrance. The improvement of total sugar release (6\% in year 1,32\% in year 2 , and $25 \%$ in year 3 ) from the transgenic switchgrass relative to the control plants revealed that the COMT downregulated switchgrass grown in the field maintained the reduced biomass recalcitrance (Fig. 2a) [18, 19]. We also observed the enhanced sugar release from unpretreated biomass and the higher saccharification yield indicating the reduced recalcitrance of COMT down-regulated switchgrass (Fig. 2b). Transplanted from the greenhouse, the switchgrass growing in the field responds and adapts to a range of stresses including pathogens, temperature and light fluctuations, and water deficits. The enzymatic hydrolysis is more efficient for younger tissue grown in 

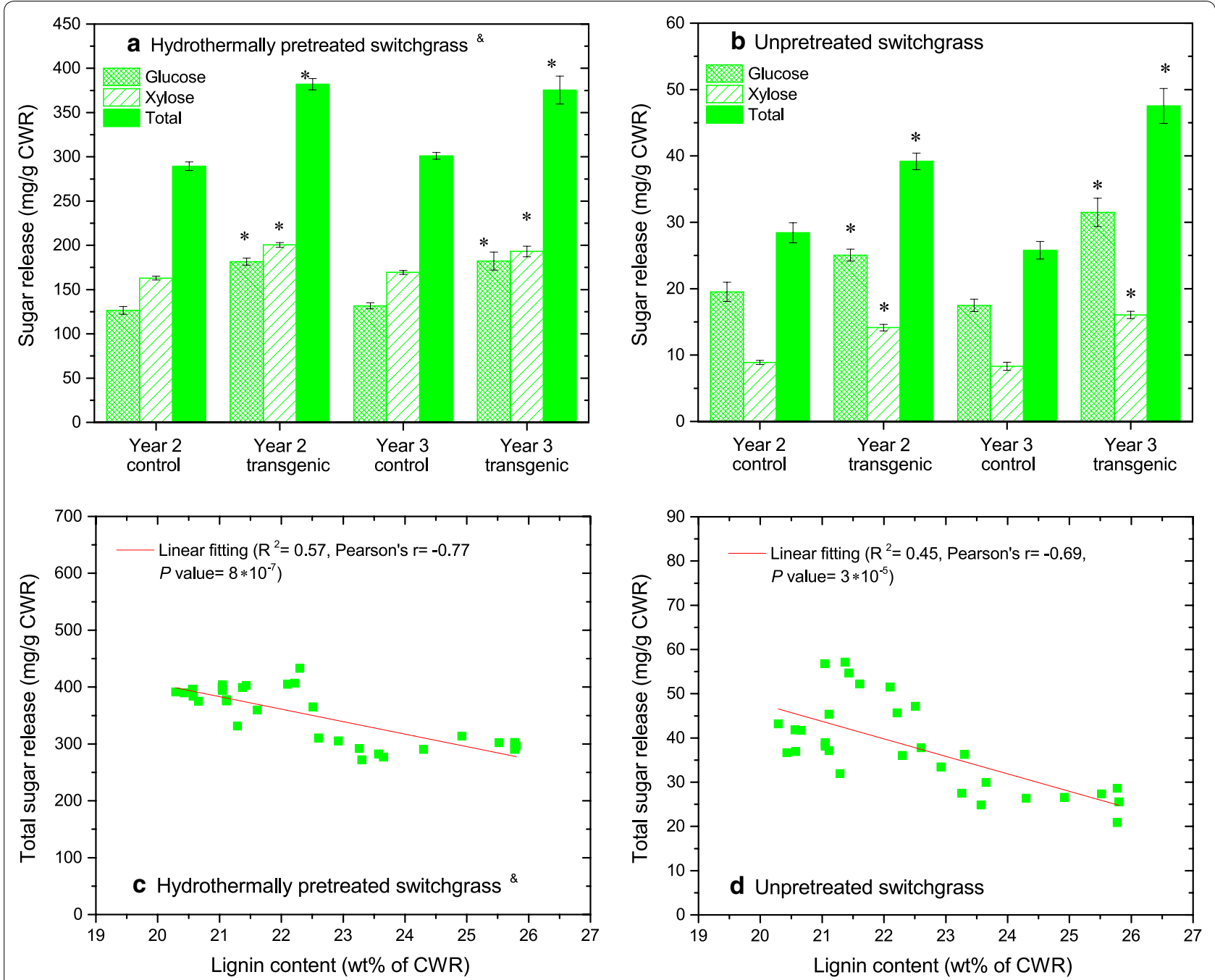

Fig. 2 Sugar release and its relationship to lignin content. Total sugar release (mg per g cell wall residues) from hydrothermally pretreated (a) and unpretreated (b) switchgrass in years 2 and 3 after 72 -h enzymatic hydrolysis (the value reported is the average of 5 biological replicates from each control group and 10 biological replicates from each transgenic group. Error bars represent standard errors.) and the relationship of total sugar (glucose and xylose) release for pretreated $(\mathbf{c})$ and unpretreated $(\mathbf{d})$ switchgrass to lignin content (wt\% of cell wall residues). An asterisk $\left(^{*}\right)$ indicates

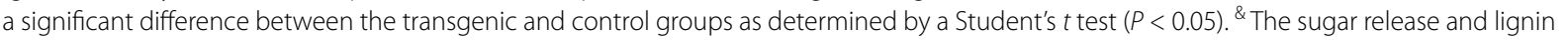
content data of year 2 and year 3 plants after pretreatment are from a previous publication $[18,19]$

the greenhouse [12] than for senesced tissue harvested from the field experiments, which is in agreement with a previous finding [29]. Taking the improved enzymatic digestibility of transgenic switchgrass with hydrothermal pretreatment and without pretreatment together, the reduced recalcitrance of the COMT down-regulated switchgrass grown under the field conditions has been retained for at least 3 years.

\section{Traits changes and their importance to cell wall recalcitrance}

Structural heterogeneity and complexity of cell wall components, such as the matrix and structures of lignin, cellulose, and hemicellulose, were thought to be factors contributing biomass recalcitrance [6, 7]. Lignin contributes to biomass recalcitrance primarily by limiting enzyme access to polysaccharides through physical shielding [30] and/or unproductive binding to enzymes [31]. To assess the association of the lignin with reduced recalcitrance in the COMT down-regulated switchgrass, lignin content was correlated with the sugar release of hydrothermally pretreated switchgrass. A dependence of sugar release on lignin content was observed in our study (Fig. 2c). Studer et al. [20] observed a similar trend in that the lignin content in natural Populus trichocarpa variants negatively correlated with sugar release. Since a potential 

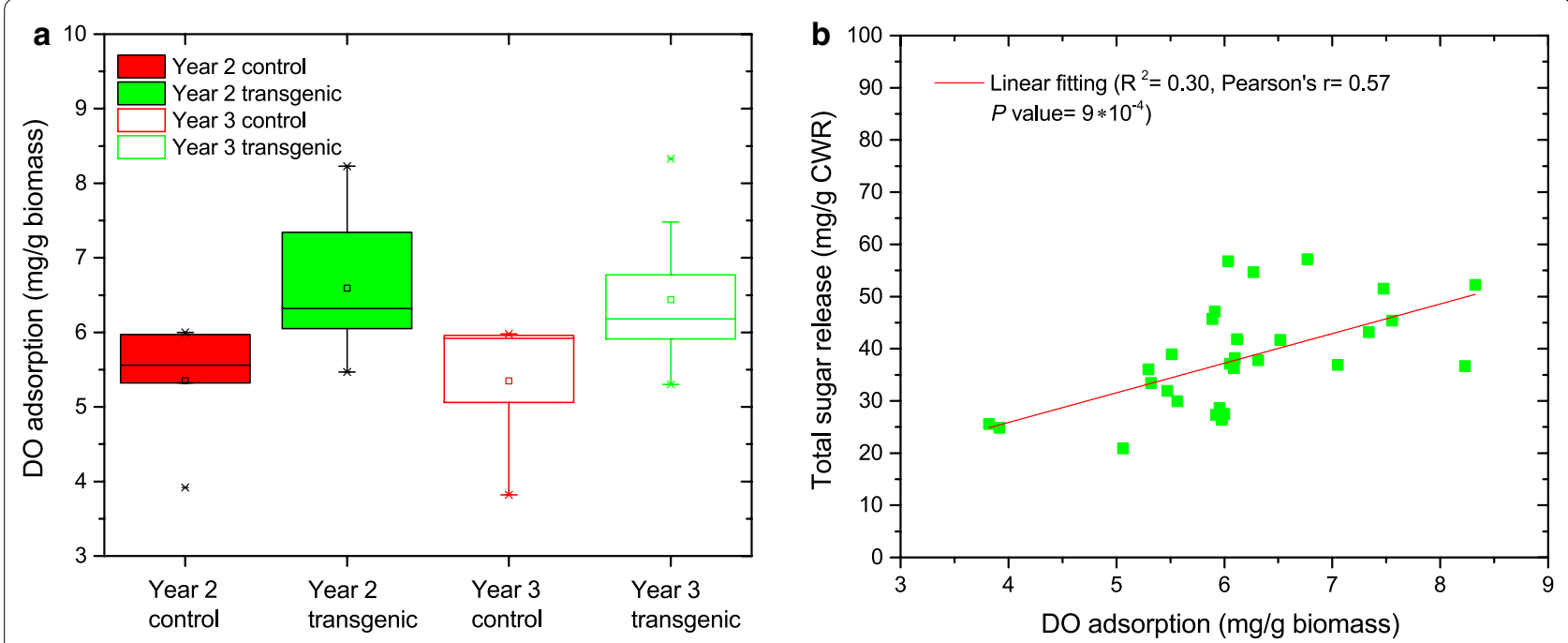

Fig. 3 Distribution of DO adsorption and its relationship to sugar release. The distribution of orange dye adsorption $\left(A_{\circ}\right)$ on unpretreated biomass measured by Simons' stain (a) and its relationship to the total sugar release (glucose and xylose) for unpretreated switchgrass (b)
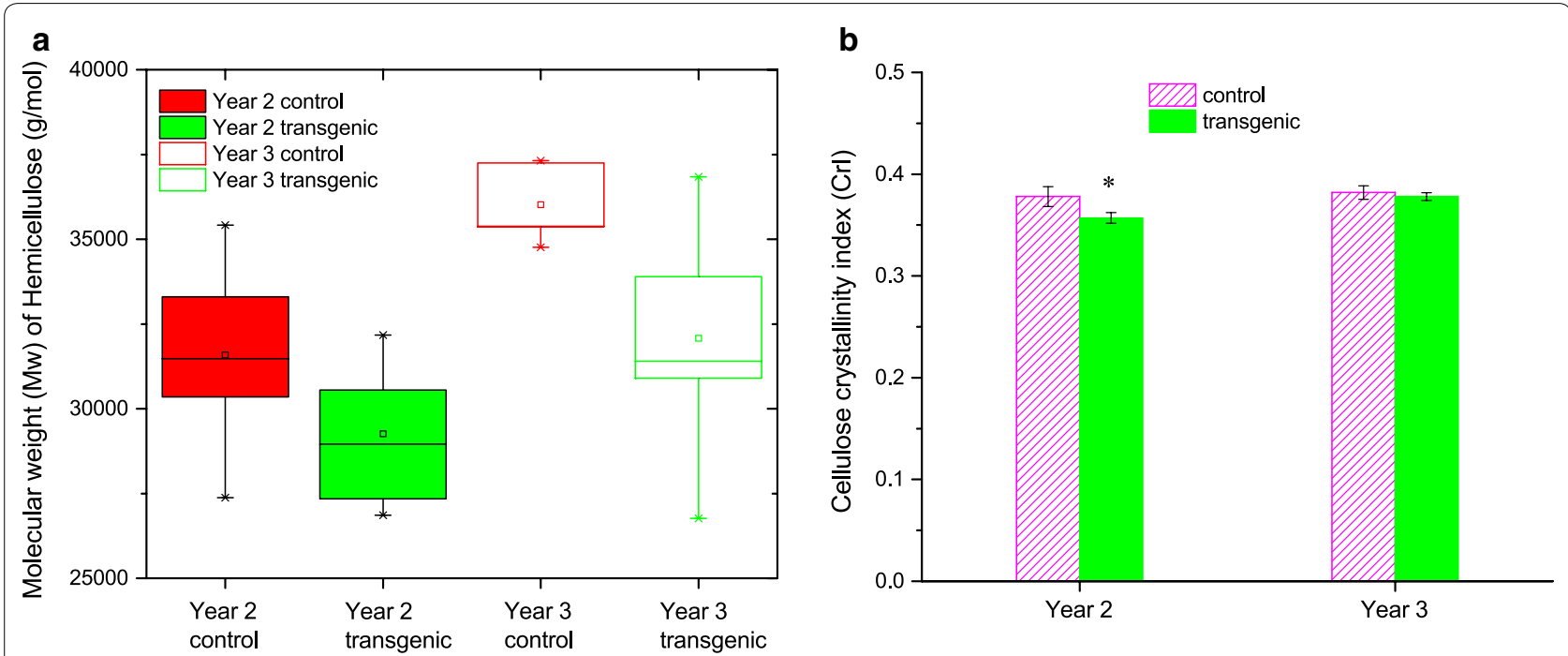

Fig. 4 Hemicellulose molecular weight distribution and cellulose crystallinity index (Crl). Distribution of weight-average molecular weight $\left(M_{w}\right)$ of hemicellulose (a) and the average $\mathrm{Crl}$ of cellulose $(\mathbf{b})$. Crl values reported are the average of 5 biological replicates from each control group and 10 biological replicates from each transgenic group. Error bars represent standard errors. An asterisk ${ }^{*}$ ) indicates a significant difference between the transgenic and control groups as determined by a Student's $t$ test $(P<0.05)$

variation of lignin could occur during pretreatment (i.e., lignin fragmentation and removal) [28], the correlation of sugar release and lignin content in unpretreated biomass was also investigated (Fig. 2d). The inverse linear correlation of enzymatic digestibility of both unpretreated and hydrothermally pretreated switchgrass and lignin content suggests that the reduced biomass recalcitrance of COMT down-regulated switchgrass was likely governed by the lignin content.
Simons' stain has been employed to assess the substrate accessibility to enzymes due to the good linear correlation between the Simons' stain results and the enzymatic digestibility of biomass [32, 33]. The $20-22 \%$ higher adsorption capacity of orange $\left(A_{\mathrm{O}}\right)$ of unpretreated transgenic switchgrass than controls in years 2 and 3 indicates that transgenic switchgrass had relatively larger cellulose accessible regions that could more readily be attached to by cellulase. In addition, the switchgrass adsorbed more 
orange than blue, and the $\mathrm{O} / \mathrm{B}$ ratio was higher for the transgenic relative to the control plants (Table 1). Due to the size difference of DB $(<5 \mathrm{~nm})$ and DO $(5-36 \mathrm{~nm})$ [21], $\mathrm{O} / \mathrm{B}$ could be used to indicate the relative proportions of pore sizes of the substrate. Considering the higher affinity of DO than $\mathrm{DB}$ on lignocellulose, higher $\mathrm{O} / \mathrm{B}$ values indicate a relatively greater proportion of larger porous regions within the transgenic switchgrass that will be mostly accommodated by DO, while the small pores could only be accessed by DB. Hence, higher $A_{\mathrm{O}}$ and $\mathrm{O} / \mathrm{B}$ values in the transgenic plants indicate that field-grown COMT-deficient switchgrass possessed more cellulose accessibility than control plants. Owing to the higher affinity of DO for substrate and the similar size of orange molecular to cellulases (e.g., Trichoderma reesei $4 \times 5 \times$ $6 \mathrm{~nm}^{3}$ ), the orange adsorption capacity by itself can be used to assess the enzyme accessibility and, therefore, susceptibility of biomass [22, 34]. The positive correlation of DO adsorption capacity and sugar release of biomass (Fig. 3b) implied that reduced biomass recalcitrance could be associated with larger biomass accessibility. The biomass with higher adsorption of DO which is attributed to larger pore structure facilitates the accommodation and penetration of enzymes during polysaccharide hydrolysis. However, the correlation between saccharification efficiency and cellulose accessibility of unpretreated switchgrass was much lower than pretreated biomass [22]. This result of relationship is consistent with the correlation of unpretreated poplar with glucose release $\left(R^{2}=0.33\right)$ [24]. Although statistically different, the increase of cellulose accessibility in the unpretreated biomass is still in a small range and could be easily sheltered by the complexity of cell wall structure.

Other factors associated with biomass recalcitrance include DP and crystallinity of cellulose and the properties of hemicellulose [7]. The DP of cellulose in either a relatively pure cellulosic substrate or lignocellulosic biomass has been thought to be one of the important factors affecting the efficiency of enzymatic hydrolysis [35]. Similar to the greenhouse-grown switchgrass [12], the cellulose DP of transgenic plants did not show significant variation from that of their controls. The crystallinity index (CrI) has been reported to be linearly proportional to the saccharification efficiency of cellulosic substrates, e.g., the CrI of Avicel was directly related to hydrolysis rate by cellulases [36]. The similarity of cellulose CrIs between transgenic and control switchgrass was also observed for the greenhouse-grown switchgrass, although the absolute values of CrIs are relatively lower, compared with those from greenhouse-grown plants (52-55\%) [12]. However, no correlation was found between enzymatic digestibility and cellulose DP (Additional file 1: Figure S2) or CrIs (Additional file 1: Figure
S4) in our study. Therefore, the small variation of cellulose CrI and DP between the transgenic and control lines suggests that cellulose CrI and DP are not contributing to the reduced recalcitrance of the field-grown COMT switchgrass.

Hemicelluloses are considered to be another factor contributing to biomass recalcitrance by limiting enzyme accessibility as a physical barrier [7]. It is interesting to find that the COMT down-regulation caused reduced hemicellulose molecular weights in the field-grown switchgrass. The molecular weight of hemicellulose was widely distributed depending on extraction conditions. Ayoub et al. [37] reported that the extraction of switchgrass hemicellulose with $18 \% \mathrm{NaOH}$ at $50{ }^{\circ} \mathrm{C}$ for $3 \mathrm{~h}$ resulted in a much lower $M_{\mathrm{n}}$ of $460 \mathrm{~g} / \mathrm{mol}$ and $M_{\mathrm{w}}$ of $3500 \mathrm{~g} / \mathrm{mol}$ due to alkaline degradation. Thus, our hemicellulose was extracted at lower temperature $\left(\sim 22{ }^{\circ} \mathrm{C}\right)$ and shorter time $(4 \mathrm{~h})$ to avoid significant degradation. Previous study has found that the high lignin content in biomass limits the extraction of hemicellulose, likely because of the presence of lignin-carbohydrate complex linkages [38]. Although the reduction of hemicellulose molecular weight in the transgenic lines is interesting, the potential reason cannot be confirmed without further investigation. Together with the changes in hemicellulose contents, our results imply that the COMT downregulation had a greater influence on hemicellulose than cellulose in switchgrass cell walls. In addition, hemicellulose in transgenic switchgrass with lower $M_{\mathrm{n}}$ and $M_{\mathrm{w}}$ tends to have shorter chains and more reducing ends, which are beneficial to exo-xylanases. However, no correlation between the hemicellulose molecular weights and sugar release (Additional file 1: Figure S3) suggests that the structural change of hemicellulose is not likely to be the major contributor to the reduced recalcitrance of the COMT down-regulated switchgrass.

\section{Conclusions}

The current study reports the differences and stability of several plant traits of plants without pretreatment: COMT-suppressed switchgrass and wild-type control with two growing seasons (years 2 and 3 ) in field trials. Overall, the reduced lignin content and recalcitrance of the transgenic plants are durable in the field for at least 3 years. Silencing of COMT in switchgrass led to increased cellulose accessibility, measured by Simons' stain. The manipulation of lignin biosynthesis in switchgrass also had an indirect influence on hemicellulose in plants demonstrated by increased xylan and galactan contents and decreased hemicellulose molecular weights. Over the latter 2-year field observation, lignin content and hemicellulose molecular weights increased significantly. The reduced lignin content and increased cell 
wall accessibility are the two important factors of those measured traits, which are likely to be associated with the reduced recalcitrance of the COMT-silenced field-grown switchgrass. The comparative observations and analysis results in this study provide a mechanistic understanding of cell wall recalcitrance in lignin-reduced mutants.

\section{Methods}

\section{Chemicals}

The enzyme cocktail Cellic CTec2 was obtained from Novozyme (Franklinton, NC). Direct Blue (DB) 1 (Pontamine Fast Sky Blue 6BX) and Direct Orange (DO) 15 (Pontamine Fast Orange 6RN) dyes were obtained from Pylam Products Co. Inc. (Garden City, NY). Peracetic acid solution (32 $\mathrm{wt} \%$ in dilute acetic acid), phenyl isocyanate (assay grade), and dichloromethane (HPLC grade) were purchased from Sigma-Aldrich (St. Louis, MO). Anhydrous pyridine (EMD, Millipore) was purchased from VWR. All the reagents and chemicals, unless otherwise noted, were used as received.

\section{Generation and growth of transgenic and control switchgrass}

In a previous study, a lowland-type switchgrass (cv. Alamo) was genetically modified by down-regulating COMT gene expression by RNAi-mediated gene silencing [12]. A scheme of the proposed lignin biosynthesis pathway involving COMT is shown (Additional file 1: Figure $\mathrm{S} 1$ ). Briefly, a $\mathrm{T}_{0}$ event was crossed with a non-transformed 'Alamo' accession to produce the $\mathrm{T}_{1}$ generation. The 10 plants of the $\mathrm{T}_{1}$-generation COMT2 line are biological replicates, each grown from separate seeds resulting from a cross between the $\mathrm{T}_{0}$-generation COMT2 event and an Alamo wild-type plant. A population of the $T_{1}$ transgenic switchgrass and its $T_{1}$ null-segregant controls were grown in Knoxville, Tennessee, USA. The 3-year experiment from this field has been described elsewhere $[18,19]$. The field trial was established in 2011, and the aboveground senesced biomass was harvested after a killing frost in December of each year from 2011 to 2013. In the current study, ten transgenic replicates for COMT2 and five corresponding null-segregant (nontransgenic control) replicates in 2012 (year 2) and 2013 (year 3) were selected for analysis. All senesced tissue samples were ground with a Wiley mill to $0.8-1.0 \mathrm{~mm}$ after oven-drying $\left(43^{\circ} \mathrm{C}, 96 \mathrm{~h}\right)$ before further analysis.

\section{Chemical compositional analysis}

The compositional analysis of switchgrass was performed as described previously [18]. Briefly, the extractive-free samples, designated as cell wall residues (CWR) in this study, were subjected to a two-step hydrolysis according to the protocol developed by NREL (http://www.nrel. gov/docs/gen/fy08/42623.pdf) using three replicates. The monomeric sugar units were quantified via a Flexar highpressure liquid chromatography (HPLC) column (Perkin Elmer, Shelton, CT) equipped with a refractive index (RI) detector, an Aminex HPX-87P carbohydrate column, and a de-ashing guard column from Bio-Rad (Hercules, CA). The lignin contents of all biomass samples were analyzed by pyrolysis molecular beam mass spectrometry (PyMBMS), as described elsewhere [18, 39].

\section{Enzymatic hydrolysis and sugar release}

Enzymatic hydrolysis of unpretreated and the resultant pretreated switchgrass was carried out in 96-well reactor plates using a high-throughput pretreatment and hydrolysis technique (HTPH) [40]. In brief, $5.00 \pm 0.30 \mathrm{mg}$ extractive-free switchgrass was loaded into custom 96-well Hastelloy reactor plates. After the addition of $250 \mu \mathrm{L}$ of water to each well, the reactor plates were sealed and pretreated for $17.5 \mathrm{~min}$ at $180{ }^{\circ} \mathrm{C}$ in a modified two-gallon Parr reactor (model 4554, Parr Instrument Company). After cooling, $40 \mathrm{~mL}$ of CTec 2 cellulase diluted in $1.0 \mathrm{M}$ citrate buffer $\mathrm{pH} 5.0$ was added to a final loading of $70 \mathrm{mg}$ protein/g glucan. After resealing the reactor plates, enzymatic hydrolysis was performed at $50{ }^{\circ} \mathrm{C}$ for $70 \mathrm{~h}$. The released glucose and xylose contents in the supernatant were quantified by sugar-specific oxidation-reduction assays [40]. If pretreatment was omitted, the samples were soaked for $4 \mathrm{~h}$ in water and then directly subjected to enzymatic hydrolysis with CTec2 as described. For each independent biomass sample, three analytical replicates were performed. The enzymatic digestibility (or saccharification yield) was reported in terms of the sugar release amount as mg sugar per $g$ CWR.

\section{Isolation of cellulose and hemicellulose}

Cellulose and hemicellulose were isolated from switchgrass biomass according to published procedures [41, 42]. The extractive-free samples were delignified by peracetic acid with $5.00 \mathrm{~g}$ loading per g biomass. The solution consistency was adjusted to $5 \%$ with deionized (DI) water and the holopulping was conducted at room temperature for $24 \mathrm{~h}$ with magnetic stirring. The solid residue, designated as holocellulose, was washed with excessive DI water $(18.0 \mathrm{M} \Omega$ ) and air dried at room temperature for $24 \mathrm{~h}$. A sub-portion of the air-dried holocellulose $(100 \mathrm{mg})$ was consecutively extracted at $25^{\circ} \mathrm{C}$ with $17.5 \%$ (wt/vol) $\mathrm{NaOH}$ solution $(5.00 \mathrm{~mL}$ ) for $2 \mathrm{~h}$, followed by $8.75 \% \mathrm{NaOH}$ solution $(10.00 \mathrm{~mL})$ for an additional $2 \mathrm{~h}$. The alkaline slurry was then filtered and rinsed with $5 \mathrm{~mL}$ of $1 \%$ acetic acid leading to a liquid fraction and a solid residue. The solid residue, namely $\alpha$-cellulose, was washed with an excess of DI water and air dried for the 
analysis of cellulose DP. The liquid fraction, rich in hemicellulose, was adjusted to $\mathrm{pH}$ 6-7 with anhydrous acetic acid. Hemicellulose was then precipitated by adding three volumes of $100 \%$ ethanol to the liquid fraction. Hemicellulose was then obtained by centrifugation at $8000 \mathrm{rpm}$ $(267 \pi \mathrm{rad} / \mathrm{s})$ for $5 \mathrm{~min}$ and freeze dried for $24 \mathrm{~h}$.

\section{Gel permeation chromatographic (GPC) analysis}

The weight-average molecular weight $\left(M_{w}\right)$ and number-average molecular weight $\left(M_{n}\right)$ of cellulose were measured by GPC after tricarbanilation, as described previously [41]. Briefly, $\alpha$-cellulose was derivatized with phenyl isocyanate in an anhydrous pyridine system prior to GPC analysis. Size-exclusion separation was performed on an Agilent 1200 HPLC system (Agilent Technologies, Inc, Santa Clara, CA) equipped with Waters Styragel columns (HR1, HR4, and HR5; Waters Corporation, Milford, MA). Number-average degree of polymerization $\left(\mathrm{DP}_{\mathrm{n}}\right)$ and weight-average degree of polymerization $\left(\mathrm{DP}_{\mathrm{w}}\right)$ of cellulose were obtained by dividing $M_{\mathrm{n}}$ and $M_{\mathrm{w}}$, respectively, by $519 \mathrm{~g} / \mathrm{mol}$, the molecular weight of the tricarbanilated cellulose repeating unit. The molecular weights of hemicellulose were measured by an Agilent 1200 series HPLC system equipped with three columns of Ultrahydrogel 120, 250, and 500 (Waters Inc.) linked in series according to [43]. The freeze-dried hemicellulose samples were dissolved in $0.2 \mathrm{M}$ sodium hydroxide $/ 0.1 \mathrm{M}$ sodium acetate $(\mathrm{pH} 13.0)$ mobile phase $(\sim 1.0 \mathrm{mg} / \mathrm{mL})$ directly and filtered through a $0.45-\mu \mathrm{m}$ filter before GPC analysis.

\section{Solid-state NMR analysis}

Solid-state NMR analysis for cellulose crystallinity was performed as described previously with minor modification [42]. The isolated cellulose samples were stored in a sealed container to prevent moisture loss. The NMR samples were prepared by packing the moisturized cellulose into 4-mm cylindrical Zirconia MAS rotors. Cross-polarization magic angle spinning (CP/MAS) NMR analysis of cellulose was carried out on a Bruker Advance-400 spectrometer operating at a frequency of $100.59 \mathrm{MHz}$ for ${ }^{13} \mathrm{C}$ in a Bruker double-resonance MAS probe head at the spinning speed of $10 \mathrm{kHz}$. CP/MAS experiments utilized a $5 \mu \mathrm{s}\left(90^{\circ}\right)$ proton pulse, $1.5 \mathrm{~ms}$ contact pulse, $4 \mathrm{~s}$ recycle delay, and 4000 scans. The cellulose crystallinity index (CrI) was determined from the areas of the crystalline and amorphous $\mathrm{C}_{4}$ signals using the following formula:

$$
\mathrm{CrI}=\frac{A_{86-92 \mathrm{ppm}}}{A_{86-92 \mathrm{ppm}}+A_{79-86 \mathrm{ppm}}} .
$$

\section{Simons' stain}

The accessibility of unpretreated switchgrass was estimated by a down-scaled Simons' stain procedure with
DB 1 and DO 15 dyes, as described previously [22, 34]. In detail, extractive-free switchgrass $(10.00 \mathrm{mg}$ oven-dry basis) was weighed into seven micro-centrifuge tubes (2 mL) individually. Phosphate-buffered saline solution $\left(\mathrm{pH}\right.$ 6.0, $\left.0.30 \mathrm{M} \mathrm{PO}_{4}^{3-}, 1.40 \mathrm{mM} \mathrm{NaCl}\right)(0.10 \mathrm{~mL})$ was added to each tube. A set of dye solutions containing $0.20,0.40$, $0.60,0.80,1.20,1.60$, and $2.00 \mathrm{mg} / \mathrm{mL}$ of both $\mathrm{DO}$ and $\mathrm{DB}$ was made and $0.50 \mathrm{~mL}$ of the solution was added to each tube. DI water $(0.40 \mathrm{~mL})$ was added to each tube to make up the final volume to $1.00 \mathrm{~mL}$ to give concentrations of DO and DB of 0.10, 0.20, 0.30, 0.40, 0.60, 0.80, and $1.00 \mathrm{mg} / \mathrm{mL}$. The centrifuge tubes were incubated at $70{ }^{\circ} \mathrm{C}$ for $6 \mathrm{~h}$ with shaking at $200 \mathrm{rpm}$ to allow dye adsorption to reach equilibrium. The absorbance of the supernatant solution after centrifugation was obtained on a Lambda 35 UV-Vis spectrophotometer at 410 and $599 \mathrm{~nm}$, which represent the wavelengths of maximum absorbance for DO and $\mathrm{DB}$, respectively. The amount of each dye adsorbed by the biomass sample was determined using the difference between the concentration of the initial added dye and the concentration of the dye in the supernatant. The maximum amount of DO or DB adsorbed to the substrate was calculated from the slope of a plot of $C / A$ versus $C$ according to the Langmuir adsorption equation shown below:

$$
\frac{C}{A}=\frac{1}{K \times A_{m}}+\frac{C}{A_{m}},
$$

where $C(\mathrm{mg} / \mathrm{mL})$ is the concentration of free dye in supernatant, $A$ (mg/g biomass) is the amount of dye adsorbed by the substrate, $K(\mathrm{~mL} / \mathrm{mg})$ is the Langmuir adsorption constant, and $A_{\mathrm{m}}(\mathrm{mg} / \mathrm{g}$ biomass $)$ is the maximum amount of dye adsorbed.

\section{Statistical analysis and plotting}

All statistical analyses were performed with Microsoft Excel 2010 and/or Origin Pro software and all figures were created using Origin Pro software. All samples representing transgenic or control lines (year 2 control, year 2 transgenic, year 3 control, and year 3 transgenic) were pair-compared (e.g., transgenic vs control and year 2 vs year 3) for such samples sets were made with parametric tests (e.g., Student's $t$ test for comparison of two means). The $t$ test was applied with equal or unequal variances based on the results of an $\mathrm{F}$ test for each comparison. A one-tail $P<0.05$ indicates that changes between compared groups were significant at $95 \%$ confidence level. The correlations between measured traits and sugar release were made across samples from all transgenic lines (10) and controls (5) in both years 2 and 3 by linear fitting. A Pearson coefficient was also calculated for guidance (although the Pearson correlation remains a consistent estimator of linearity, the test of its significance cannot be trusted without normality assumption). 


\section{Additional file}

Additional file 1. Supporting figures and tables of understanding the reduced cell wall recalcitrance of field-grown COMT Down-regulated switchgrass. Figure S1. Scheme of proposed lignin biosynthesis involving COMT. Figure S2. Relationship of cellulose DP to glucose release efficiency of unpretreated switchgrass. Figure $\mathbf{S 3}$. Relationship of hemicellulose molecular weights to xylose release efficiency of unpretreated switchgrass. Figure S4. Relationship of Cellulose crystallinity (Crl) to glucose release unpretreated switchgrass. Table S1. Original data used for Fig. 1: Chemical composition (per g cell wall residue) of field-grown switchgrass in years 2 and 3 . The values reported are the average of 5 biological replicates from each control group, and 10 biological replicates from each transgenic group. Student $t$ test was used as a statistical analysis for the difference between the transgenic and control groups.

Table S2. Data used for Fig. 2a and b: Sugar release (mg per g cell wall residues) from hydrothermally pretreated (a) and unpretreated (b) switchgrass in years 2 and 3 after 72 h enzymatic hydrolysis (the value reported is the average of 5 biological replicates from each control group, and 10 biological replicates from each transgenic group). Student $t$ test was used as a statistical analysis for the difference between the transgenic and control groups. Table S3. Original data used for Fig. 2c: the relationship of total sugar (glucose and xylose) release for pretreated switchgrass from enzymatic hydrolysis to lignin content (wt\% of cell wall residues). Table S4. Original data used for Fig. 2 d: the relationship of total sugar (glucose and xylose) release for unpretreated switchgrass from enzymatic hydrolysis to lignin content (wt\% of cell wall residues). Table S5. Original data used for Figs. 3 and 4: distribution of DO adsorption and relationship of DO its relationship to sugar release (Fig. 3). Hemicellulose molecular weight distribution and Cellulose crystallinity index (Crl) (Fig. 4). Student's $t$ test was used as a statistical analysis for the difference between the transgenic and control groups. Table S6. Student's $t$ test results of traits difference in field-grown switchgrass between year 2 and 3 .

\section{Abbreviations}

$\mathrm{A}_{0}$ : maximum adsorption of orange dye; COMT: caffeic acid O-methyltransferase; CP/MAS: cross-polarization magic angle spinning; DB: direct blue dye; Crl: crystallinity index; $\mathrm{DO}$ : direct orange dye; $\mathrm{DP}_{\mathrm{n}}$ : number-average degree of polymerization; $D_{\mathrm{w}}$ : weight-average degree of polymerization; $\mathrm{M}_{\mathrm{n}}$ : numberaverage molecular weight; $\mathrm{M}_{\mathrm{w}}$ : weight-average molecular weight; Py-MBMS: pyrolysis molecular beam mass spectrometry.

\section{Authors' contributions}

$\mathrm{ML}, \mathrm{YP}$, and $\mathrm{AR}$ conceived and designed the research. CF, RD, and ZW developed the transgenic plant and participated in the design of this study. $\mathrm{HB}, \mathrm{MM}$, and NS grew, harvested, and ground the plant and participated in the design of this study. ML, YP, CY, and AR carried out the measurement of degree of polymerization and crystallinity of cellulose, molecular weight of hemicellulose, and cellulose accessibility. EG and CD carried out the chemical compositional analysis. SD, EG, and TS carried out the analysis for sugar release. TT and NE participated in the cellulose and hemicellulose isolation. RS and $\mathrm{MD}$ carried out the lignin content analysis. All the authors were involved in the discussion of the data, and wrote and approved the paper. All authors read and approved the final manuscript.

\section{Author details}

${ }^{1}$ BioEnergy Science Center (BESC), Oak Ridge National Laboratory (ORNL), Oak Ridge, TN, USA. ${ }^{2}$ BioSciences Division, ORNL, Oak Ridge, TN, USA. ${ }^{3}$ UTORNL Joint Institute for Biological Sciences, Oak Ridge, TN, USA. ${ }^{4}$ Biosciences Center, National Renewable Energy Laboratory (NREL), Golden, CO, USA. ${ }^{5}$ National Bioenergy Center, NREL, Golden, CO, USA. ${ }^{6}$ Department of Plant Sciences, University of Tennessee, Knoxville, TN, USA. ${ }^{7}$ Forage Improvement Division, The Samuel Roberts Noble Foundation, Ardmore, OK, USA. ${ }^{8}$ BioDiscovery Institute and Department of Biological Sciences, University of North Texas, Denton, TX, USA. ${ }^{9}$ Department of Chemical and Biomolecular Engineering \& Department of Forestry, Wildlife and Fisheries, University of Tennessee, Knoxville, TN, USA.

\section{Acknowledgements}

We thank Susan K. Holladay for coordinating data sharing. We also thank Dr. Xianzhi Meng for his help in statistical analysis and discussion. This manuscript has been authorized by UT-Battelle, LLC under Contract No. DE-AC0500OR22725 with the US Department of Energy. This study was supported and performed as part of the BioEnergy Science Center (BESC). The BESC is a U.S. Department of Energy Bioenergy Research Center supported by the Office of Biological and Environmental Research in the DOE Office of Science.

This manuscript has been authored by UT-Battelle, LLC under Contract No. DE-AC05-00OR22725 with the U.S. Department of Energy. The publisher, by accepting the article for publication, acknowledges that the United States Government retains a non-exclusive, paid-up, irrevocable, world-wide license to publish or reproduce the published form of this manuscript, or allow others to do so, for United States Government purposes. The Department of Energy will provide public access to these results of federally sponsored research in Accordance with the DOE Public Access Plan (http://energy.gov/downloads/ doe-public-access-plan).

\section{Competing interests}

The authors declare that they have no competing interests.

\section{Availability of supporting data}

We provide supporting data, if necessary, for the publication of the article.

\section{Funding}

This work was supported by the BioEnergy Science Center, a U.S. Department of Energy Bioenergy Research Center supported by the Office of Biological and Environmental Research in the DOE Office of Science. This manuscript has been authored by a contractor of the U.S. Government under Contract No. DE-AC05-00OR22725.

Received: 17 June 2016 Accepted: 23 December 2016 Published online: 03 January 2017

\section{References}

1. Ragauskas AJ, Williams CK, Davison BH, Britovsek G, Cairney J, Eckert CA Frederick WJ, Hallett JP, Leak DJ, Liotta CL. The path forward for biofuels and biomaterials. Science. 2006;311(5760):484-9.

2. Lynd LR. Overview and evaluation of fuel ethanol from cellulosic biomass: technology, economics, the environment, and policy. Annu Rev Energy Environ. 1996;21(1):403-65.

3. David K, Ragauskas AJ. Switchgrass as an energy crop for biofuel production: a review of its ligno-cellulosic chemical properties. Energ Environ Sci. 2010;3(9):1182-90.

4. Schmer MR, Vogel KP, Mitchell RB, Perrin RK. Net energy of cellulosic ethanol from switchgrass. Proc Natl Acad Sci. 2008;105(2):464-9.

5. Demain AL. Biosolutions to the energy problem. J Ind Microbiol Biotechnol. 2009;36(3):319-32.

6. Himmel ME, Ding S-Y, Johnson DK, Adney WS, Nimlos MR, Brady JW, Foust TD. Biomass recalcitrance: engineering plants and enzymes for biofuels production. Science. 2007;315(5813):804-7.

7. Zhao X, Zhang L, Liu D. Biomass recalcitrance. Part l: the chemical compositions and physical structures affecting the enzymatic hydrolysis of lignocellulose. Biofuel Bioprod Biorefin. 2012;6(4):465-82.

8. Chandra RP, Bura R, Mabee W, Berlin DA, Pan X, Saddler J. Substrate pretreatment: the key to effective enzymatic hydrolysis of lignocellulosics? Biofuels. 2007;108:67-93.

9. Nakagame S, Chandra RP, Saddler JN. The effect of isolated lignins, obtained from a range of pretreated lignocellulosic substrates, on enzymatic hydrolysis. Biotechnol Bioeng. 2010;105(5):871-9.

10. Mosier N, Wyman C, Dale B, Elander R, Lee Y, Holtzapple M, Ladisch M. Features of promising technologies for pretreatment of lignocellulosic biomass. Bioresour Technol. 2005;96(6):673-86.

11. Pienkos PT, Zhang M. Role of pretreatment and conditioning processes on toxicity of lignocellulosic biomass hydrolysates. Cellulose. 2009;16(4):743-62. 
12. Fu C, Mielenz JR, Xiao X, Ge Y, Hamilton CY, Rodriguez M, Chen F, Foston $M$, Ragauskas A, Bouton J. Genetic manipulation of lignin reduces recalcitrance and improves ethanol production from switchgrass. Proc Natl Acad Sci. 2011;108(9):3803-8.

13. Chen F, Dixon RA. Lignin modification improves fermentable sugar yields for biofuel production. Nat Biotechnol. 2007;25(7):759-61.

14. Louie GV, Bowman ME, Tu Y, Mouradov A, Spangenberg G, Noel JP. Structure-function analyses of a caffeic acid O-methyltransferase from perennial ryegrass reveal the molecular basis for substrate preference. Plant Cell. 2010;22(12):4114-27.

15. Guo D, Chen F, Inoue K, Blount JW, Dixon RA. Downregulation of caffeic acid 3-O-methyltransferase and caffeoyl CoA 3-O-methyltransferase in transgenic alfalfa: impacts on lignin structure and implications for the biosynthesis of $\mathrm{G}$ and S lignin. Plant Cell. 2001;13(1):73-88.

16. Tschaplinski TJ, Standaert RF, Engle NL, Martin MZ, Sangha AK, Parks JM, Smith JC, Samuel R, Jiang N, Pu Y. Down-regulation of the caffeic acid O-methyltransferase gene in switchgrass reveals a novel monolignol analog. Biotechnol Biofuels. 2012;5(71):1.

17. Ragauskas A, Pu Y, Samuel R, Jiang N, Fu C, Wang Z-Y. Structural characterization of lignin in wild-type versus COMT down-regulated switchgrass. Front Energ Res. 2014;1:14.

18. Baxter HL, Mazarei M, Labbe N, Kline LM, Cheng Q, Windham MT, Mann DG, Fu C, Ziebell A, Sykes RW. Two-year field analysis of reduced recalcitrance transgenic switchgrass. Plant Biotechnol J. 2014;12(7):914-24.

19. Baxter HL, Mazarei M, Fu C, Cheng Q, Turner GB, Sykes RW, Windham MT, Davis MF, Dixon RA, Wang Z-Y. Time course field analysis of COMT-downregulated switchgrass: lignification, recalcitrance, and rust susceptibility. Bioenerg Res 2016:1-14

20. Studer MH, DeMartini JD, Davis MF, Sykes RW, Davison B, Keller M, Tuskan GA, Wyman CE. Lignin content in natural Populus variants affects sugar release. Proc Natl Acad Sci. 2011;108(15):6300-5.

21. Yu X, Minor JL, Atalla RH. Mechanism of action of Simons'stain. Tappi J. 1995;78:175.

22. Chandra RP, Saddler JN. Use of the Simons' staining technique to assess cellulose accessibility in pretreated substrates. Ind Biotechnol. 2012;8(4):230-7.

23. Yu X, Atalla RH. A staining technique for evaluating the pore structure variations of microcrystalline cellulose powders. Powder Technol. 1998;98(2):135-8.

24. Meng X, Pu Y, Yoo CG, Li M, Bali G, Park D-Y, Gjersing E, Davis M, Wellington M, Tuskan G. An in-depth understanding of biomass recalcitrance using natural poplar variants as the feedstock. ChemSusChem. 2016. doi:10.1002/cssc.201601303.

25. Dumitrache A, Akinosho H, Rodriguez M, Meng X, Yoo CG, Natzke J, Engle NL, Sykes RW, Tschaplinski TJ, Muchero W. Consolidated bioprocessing of Populus using Clostridium (Ruminiclostridium) thermocellum: a case study on the impact of lignin composition and structure. Biotechnol Biofuels. 2016;9(1):1.

26. Pedersen JF, Vogel KP, Funnell DL. Impact of reduced lignin on plant fitness. Crop Sci. 2005;45(3):812-9.

27. Moura JCMS, Bonine CAV, Viana J, de Oliveira Fernandes Dornelas MC, Mazzafera P. Abiotic and biotic stresses and changes in the lignin content and composition in plants. Journal of integrative plant biology. 2010;52(4):360-76.

28. Pu Y, Hu F, Huang F, Davison BH, Ragauskas AJ. Assessing the molecular structure basis for biomass recalcitrance during dilute acid and hydrothermal pretreatments. Biotechnol Biofuels. 2013:6(1):1.

29. Kim Y, Mosier NS, Ladisch MR, Pallapolu VR, Lee Y, Garlock R, Balan V, Dale BE, Donohoe BS, Vinzant TB. Comparative study on enzymatic digestibility of switchgrass varieties and harvests processed by leading pretreatment technologies. Bioresour Technol. 2011;102(24):11089-96.
30. Chang VS, Holtzapple MT. Fundamental factors affecting biomass enzymatic reactivity. In: Twenty-First Symposium on biotechnology for fuels and chemicals. Springer; 2000. p. 5-37.

31. Esteghlalian AR, Srivastava V, Gilkes N, Gregg DJ, Saddler JN. An overview of factors influencing the enzymatic hydrolysis of lignocellulosic feedstocks. In: Himmel ME, Baker JO, Saddler JN, editors. In glycosyl hydrolases for biomass conversion. Washington, DC: American Chemical Society; 2000. p. 100-11.

32. Esteghlalian AR, Bilodeau M, Mansfield SD, Saddler JN. Do enzymatic hydrolyzability and Simons'stain reflect the changes in the accessibility of lignocellulosic substrates to cellulase enzymes? Biotechnol Prog 2001;17(6):1049-54

33. Meng X, Foston M, Leisen J, DeMartini J, Wyman CE, Ragauskas AJ. Determination of porosity of lignocellulosic biomass before and after pretreatment by using Simons' stain and NMR techniques. Bioresour Technol. 2013:144:467-76.

34. Meng X, Wells T, Sun Q, Huang F, Ragauskas A. Insights into the effect of dilute acid, hot water or alkaline pretreatment on the cellulose accessible surface area and the overall porosity of Populus. Green Chem. 2015;17(8):4239-46.

35. Mansfield SD, Mooney C, Saddler JN. Substrate and enzyme characteristics that limit cellulose hydrolysis. Biotechnol Prog. 1999:15(5):804-16.

36. Hall M, Bansal P, Lee JH, Realff MJ, Bommarius AS. Cellulose crystallinity - a key predictor of the enzymatic hydrolysis rate. FEBS J. 2010;277(6):1571-82

37. Ayoub A, Venditti RA, Pawlak JJ, Sadeghifar H, Salam A. Development of an acetylation reaction of switchgrass hemicellulose in ionic liquid without catalyst. Ind Crop Prod. 2013;44:306-14.

38. Liu K-X, Li H-Q, Zhang J, Zhang Z-G, Xu J. The effect of non-structural components and lignin on hemicellulose extraction. Bioresour Technol. 2016:214:755-60.

39. Sykes R, Yung M, Novaes E, Kirst M, Peter G, Davis M. High-throughput screening of plant cell-wall composition using pyrolysis molecular beam mass spectroscopy. Biofuels 2009: 169-183.

40. Selig MJ, Tucker MP, Sykes RW, Reichel KL, Brunecky R, Himmel ME, Davis MF, Decker SR. ORIGINAL RESEARCH: lignocellulose recalcitrance screening by integrated high-throughput hydrothermal pretreatment and enzymatic saccharification. Ind Biotechnol. 2010;6(2):104-11.

41. Kumar R, Hu F, Hubbell CA, Ragauskas AJ, Wyman CE. Comparison of laboratory delignification methods, their selectivity, and impacts on physiochemical characteristics of cellulosic biomass. Bioresour Technol. 2013:130:372-81.

42. Foston MB, Hubbell CA, Ragauskas AJ. Cellulose isolation methodology for NMR analysis of cellulose ultrastructure. Materials. 2011;4(11):1985-2002.

43. Cao S, Pu Y, Studer M, Wyman C, Ragauskas AJ. Chemical transformations of Populus trichocarpa during dilute acid pretreatment. RSC Adv. 2012;2(29):10925-36.

\section{Submit your next manuscript to BioMed Central and we will help you at every step:}

- We accept pre-submission inquiries

- Our selector tool helps you to find the most relevant journal

- We provide round the clock customer support

- Convenient online submission

- Thorough peer review

- Inclusion in PubMed and all major indexing services

- Maximum visibility for your research

Submit your manuscript at www.biomedcentral com/submit 